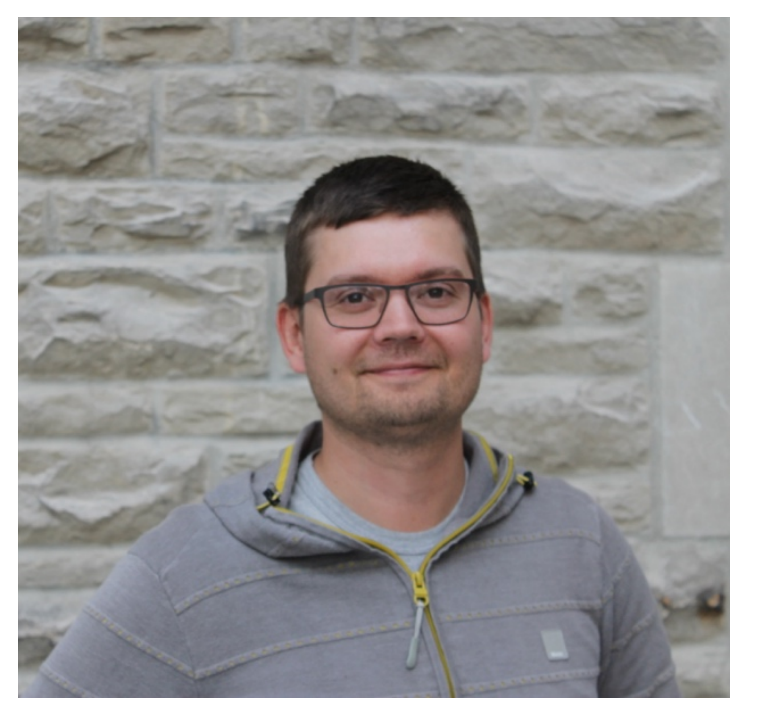

\title{
Western Faculty Profile: Dr. Andrew Pruszynski
}

\author{
Joselia Carlos ${ }^{1}$ \\ ${ }^{1}$ Faculty of Science, Western University, London, Canada \\ No conflicts of interest declared
}

\section{Background Information}

Dr. Andrew Pruszynski completed his undergraduate degree in electrical engineering at Simon Fraser University. His honours thesis supervisor thought that people who had just suffered from a stroke should start rehabilitation as quickly as possible. With walking being one of the first problems associated with stroke, Dr. Pruszynski decided to design a robot for gait rehabilitation.

Although the robot turned out to be fully functional, Dr. Pruszynski was unsure how to fully apply the technology. "We designed the technology, but no one said how to use the robot for the rehabilitation process." As a result, he decided to pursue research along these lines.

He moved to Kingston, Ontario, where he pursued a Ph.D. in neuroscience at Queen's University. Instead of building robots and focusing on gait, he concentrated more on the idea of reaching, more specifically, the fundamental mechanisms of how the brain controls the movement of reaching. He eventually moved to Sweden to do his post-doc at Umeå University. Towards the end of his degree, his interests shifted from the motor aspects of reaching to the sensory aspects of reaching.

"If I'm reaching for a coffee cup, then, of course, I really want the coffee. But what's key to that are those touch events that happen when you grab the cup and how those somatosensory or those inputs from the body are integrated into this movement." He then came here, to the University of Western Ontario three years ago as an assistant professor in the department of Physiology and Pharmacology at the Schulich School of Medicine and Dentistry. He currently teaches a few undergraduate courses offered in the department, most notably, Physiology 3120 , and has been appointed Tier 2 Canada Research Chair of Sensorimotor Neuroscience.

Dr. Pruszynski stated that after he finished his undergraduate degree, he could have worked in the industry as an engineer, which he originally intended to do. At the time, however, he valued his intellectual freedom. He found the freedom to poke around in different directions something extremely fascinating and worth pursuing.

"I remember the moment precisely, building that robot and being so happy about it and then asking people 'okay, what do we do with this thing?' That turned out to be the really hard part. At the time, I had this idea of building this complicated robot that I thought was so tricky, but actually turned out to be trivial compared to the more complicated biological problems of 'okay now you have this machine, what will you do with it?' I was then shocked by how little we [know] at the frontiers of this discipline. There are just really basic things that are so complicated and remain to be penetrated. That's what made me do a Ph.D. because I was like, okay, if you want to solve this kind of problem, being an engineer is not really helpful at this point. You really need to figure out the biology side here."

\section{Current Research Interests}

Dr. Pruszynski's lab researches basic neural mechanisms that underlie reaching, grasping, and object manipulation, with a specific focus on sensory inputs that drive these processes. They perform experiments involving human behaviour and animal neurophysiological, wherein they record specific neurons activity from the brain in subjects performing certain behaviours.

Recently, his lab has discovered a new finding about first order tactile neurons. These neurons are typically thought to be very simple processes in the peripheral nervous system that funnel information to the brain. In doing so, computations in the brain occur, which eventually tell you what object you are touching or what you should be doing. However, his lab has found that these tactile neurons eventually branch and innervate many mechanoreceptors in the skin. They have also discovered that the same computations that occur in the brain also happen in the branches of the tactile neurons in the periphery. His lab has been, more recently, studying these computations that happen in these branches. 
As a result of this new finding, the general perspective on treating peripheral nerve injuries has changed. Originally, it was thought that neurons in the periphery had no function and were simply relay wires to the central nervous system. However, this was not the case. Now, when treating patients with peripheral nerve injuries, healthcare professionals must account for not only the regrowth of these neurons, but also for the computational processes involved as well-they need to ensure that the same computational processes before the injury are present as well.

\section{Experience as a Researcher}

Dr. Pruszynski has stated that although he is very thankful to be surrounded by well-established labs here at Western, his time here can also be quite stressful at times. In research, there is always the struggle of encountering the unknown. However, Dr. Pruszynski has stated that as a scientist, he is expected to put himself in this circumstance to ensure he is actually making progress.

"When you encounter the unknown, you don't know what's there. A lot of the times, nothing is there. If there's a student who is consistently getting great results, I start asking the question, 'okay, are we doing anything interesting here?' You need to put yourself in a position where you're making progress. You're setting yourself up for that failure. Of course, you don't want to be always failing, you want to have successes too. But, you need to be in a place where you're comfortable with that difficulty." Despite the struggles he has encountered as a researcher, Dr. Pruszynski has two favourite aspects about research: 1 . The flexibility that comes with being a scientist 2 . The interaction with young students.

Dr. Pruszynski likes that he can choose what he researches and that he is in control of the direction of where his research is going to go. "If I lose interest in this particular aspect of my work, but then I get really excited about another aspect, I'm in control of deciding where my energy is going to go. It's really like owning your own small business. That's a cool feeling."

Dr. Pruszysnki also enjoys working with a cohort of people in their early twenties who are currently in an important stage of their careers. They still have many opportunities ahead of them, and it is the students' thirst for knowledge that help keep him motivated. For Dr. Pruszynski, helping these students along their path brings about a very rewarding feeling.

\section{Advice on Getting Involved as an Undergrad and for Future Neuroscientists}

In terms of getting involved as an undergraduate student, Dr. Pruszynski has advised to contact professors and simply ask them if they have any research positions available. Dr. Pruszynski has added that he is always looking for keen undergraduate students. However, he only has so many spots in his lab, so it is important to reach out to professors early. With that being said, Dr. Pruszynski has stated that there will always be a lot of professors who hold empty research positions for undergraduate students, so there is no harm in contacting them.

For fellow future neuroscientists, he has commented that neuroscience is not a discipline, but rather it is a "broad thing". $\mathrm{He}$ has advised undergraduate students to become masters in their own respective discipline, whether it is physiology, pharmacology, computer science, engineering, etc. All of these disciplines are relevant to neuroscience from different perspectives. After becoming an expert within one's respective discipline, one can then apply that to studying neuroscience.

"Get a toolkit, and apply that to studying the nervous system. I think that's a better path forward than just jumping in and saying what you're interested in is the brain. There are so many different layers of abstraction in the brain. For example, even though I'm a professor of neuroscience, I'm not a molecular biologist. I don't understand those things. There are people within neuroscience such as biologists and computer scientists that collaborate together, and it is how these people work together that makes up neuroscience."

\section{To Learn more on Dr. Pruszynski's lab and research, please visit the following websites:}

\author{
Physiology and Pharmacology profile \\ http://www.schulich.uwo.ca/physpharm/people/bios/faculty/prusz \\ ynski_andrew.html
}

Pruszynski lab

http://www.pruszynskilab.com 